\title{
Shape distortion analysis of drawing die by optical 3D scanning
}

\author{
Ladislav Morovič ${ }^{1, *}$, Ján Urminský ${ }^{1}$, and Martin Ridzoñ ${ }^{2}$ \\ ${ }^{1}$ Slovak University of Technology in Bratislava, Faculty of Materials Science and Technology in \\ Trnava, Institute of Production Technologies, Jána Bottu 2781/25, 91724 Trnava, Slovak Republic \\ ${ }^{2}$ ŽP Výskumno-vývojové centrum s.r.o. (ŽP Centre of research and development Ltd.), Železiarne \\ Podbrezová a.s., Kolkáreň 35, 97681 Podbrezová, Slovak Republic
}

\begin{abstract}
The contribution dealing with analysis of drawing die shape distortion using optical 3D scanning. The wear of drawing die has a significant influence on the shape stability of the produced tubes. Early identification and determination of wear on the drawing die leads to elimination of production errors. Metrological measuring systems can be used to analyse shape distortion. The optical 3D scanner GOM ATOS II TripleScan SO MV170 (measuring volume: $170 \times 130 \times 130 \mathrm{~mm}$; camera resolution $2448 \times 2050 \mathrm{px}(5 \mathrm{Mpx})$; measuring point distance: 0.07059 $\mathrm{mm}$ ) was used for experimental measurement of drawing die. The 3D scanned weared drawing die was compared with the reference CAD model. The result of the comparison is the colour deviation map of drawing die's shape and various inspection sections.
\end{abstract}

\section{Introduction}

Tubes are made of various materials, in different sizes and by different manufacturing technologies. In addition to steel tubes, carbon fiber tubes (and tubular parts) are also being produced nowadays [1, 2]. Except for drawing method of steel tubes, there is also the production of steel tubes (and tubular parts) by hydroforming [3,4]. The tube production is a wide field of research and many publications deal with it $[5,6]$.

The contribution describes the suitability of using the optical 3D scanner GOM ATOS to measure the shape distortion of drawing die caused by tool wear. The aforementioned drawing die is a tool for production of seamless tubes made of steel by precision cold drawing (without mandrel - Fig. 1 - left, Fig. 2).

It is very important to establish when the limit tool wear occurs in the case of tube production. Monitoring and better understanding of the tool wear process leads to increased tool exploitation efficiency. Knowledge of tool wear process would allow better use of high strength steels or other materials for tool production. Higher forces cause premature adhesion and abrasive wear, thereby shortening tool life. Another advantage would be that there was no overproduction of tools. This could support the economical production of small series of tools with cost-effective process settings [7].

\footnotetext{
*Corresponding author: ladislav.morovic@stuba.sk
} 
Appropriate adjustments of lubrication process minimizing the amount of lubricant that have a positive impact on the environment in addition to the economic impact. In the case of controlled tool wear, a stable production process can be achieved without fluctuations in the process results [7-9].

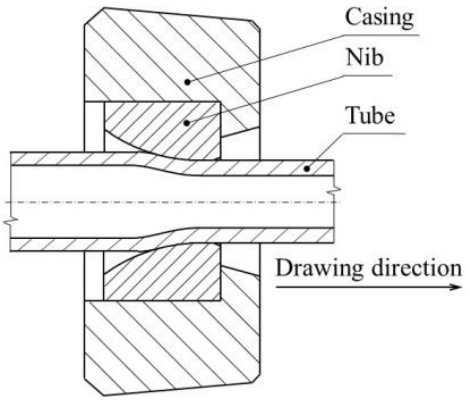

a)

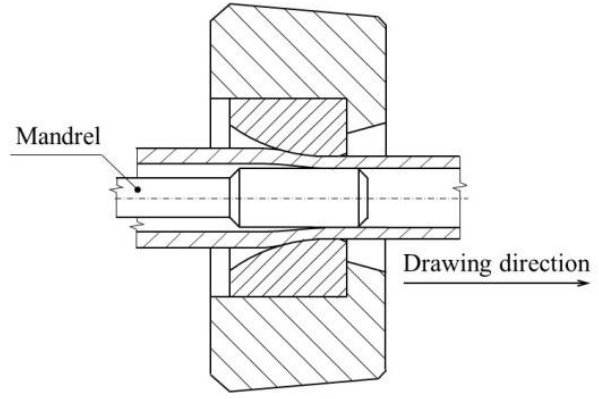

b)

Fig. 1. Drawing die (casing + nib) - seamless steel tube production by precision cold drawing: a) hollow drawing, b) drawing on fixed mandrel.

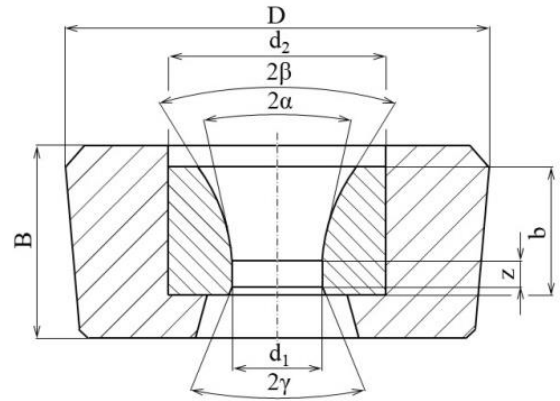

$\mathrm{d}_{1} \quad$ - Hole diameter

$\mathrm{d}_{2} \quad$ - Nib diameter

D - Casing diameter

b - Nib height

z - Bearing length

B - Casing height

$2 \alpha$ - Reduction angle

$2 \beta$ - Bell

$2 \gamma$ - Back relief

Fig. 2. Drawing die - characteristic features.

\section{Experimental method}

The object of the experimental measurement was a drawing die with a nib diameter $Ø 18.04$ $\mathrm{mm}$. The drawing die consist of casing and nib (Fig. 1, Fig. 2).

The casing is made of steel EN E335 (DIN St60-2, W. Nr. 1.0060, STN 11600), the chemical composition is in Table 1. It is a non-alloyed structural steel, which is resistant to static and dynamic loads. It is used for the production of gears, shafts, screws, nuts, clamping elements, etc. [10].

The nib is made of tungsten carbide and cobalt (GJ11), the chemical composition is in Table 2. The material GJ11 is suitable for tool making.

Table 1. Chemical composition of steel E335 [10].

\begin{tabular}{|l|c|c|c|}
\hline Element & $\mathrm{P}$ & $\mathrm{S}$ & $\mathrm{N}$ \\
\hline Weight $\%$ & $\max 0.055$ & $\max .0 .055$ & $\max 0.014$ \\
\hline
\end{tabular}

Table 2. Chemical composition of material GJ11 [11].

\begin{tabular}{|l|c|c|}
\hline Element & WC & Co \\
\hline Weight \% & 89 & 11 \\
\hline
\end{tabular}

Experimental measurements of the drawing die were performed by the optical 3D scanner GOM ATOS II TripleScan SO MV170, which is available at Centre of Excellence of 5-Axis Machining at the Faculty of Materials Science and Technology in Trnava, Slovak University of Technology in Bratislava (Fig. 3). 
The abovementioned digitization devices belong to the group of non-contact data acquisition methods of point coordinates. They use the active triangulation method, which is based on obtaining the coordinates of the surface points of the measured object by projecting patterns (i.e. fringe projection) onto the surface while $3 \mathrm{D}$ scanning is simultaneous [12-14].

The 3D scanner uses the projector and two camera system. A digital model of the measured object is created by polygonization from the obtained point cloud. Shiny and dark surfaces, transparent objects make problems for 3D scanning with structured light. Antireflection agents are currently being used to eliminate the problem and are applied to the surface of the object to be measured [12-14].

It was necessary to adjust the drawing die surface before digitizing. A titanium powder mixed with alcohol was applied by airbrush to make matt surface. The layer thus applied according to [15] has a thickness in micrometers.

For automatization of 3D digitization process, the rotary table was used. For increase the merging accuracy of individual measurements (i.e. scans) into one project, uncoded reference points was used. The digital 3D model of the $3 \mathrm{D}$ scanned part is obtained by polygonization of the point cloud acquired by $3 \mathrm{D}$ scanning.

The evaluation was performed in the software GOM ATOS Professional V7.5 SR2.

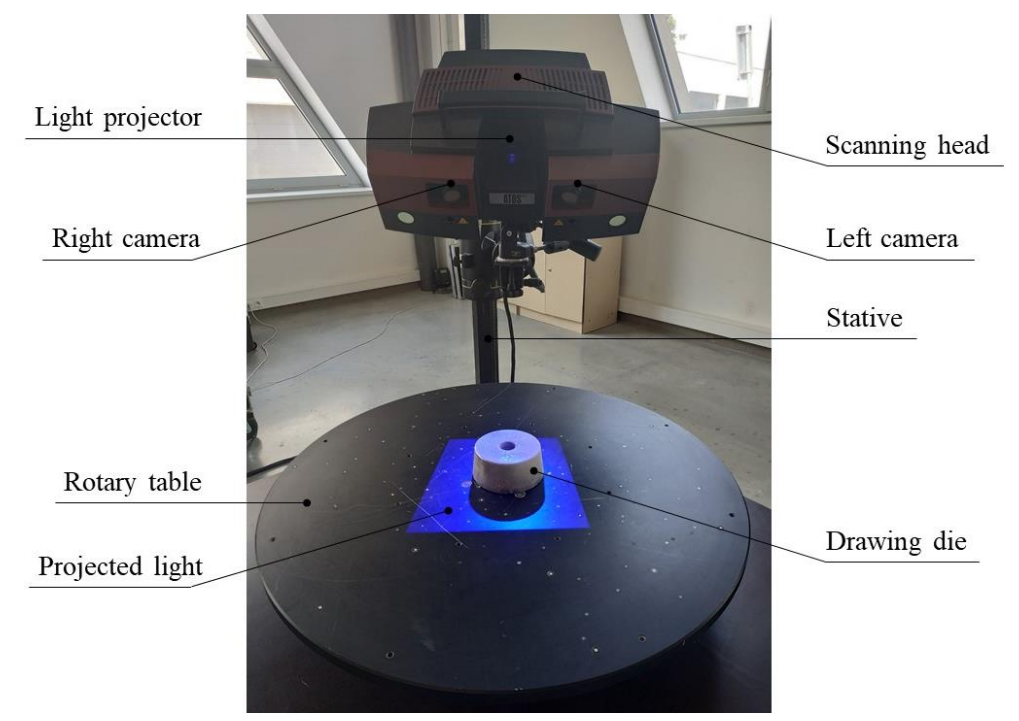

Fig. 3. 3D digitizing of the drawing die by optical 3D scanner GOM ATOS II TripleScan SO MV170.

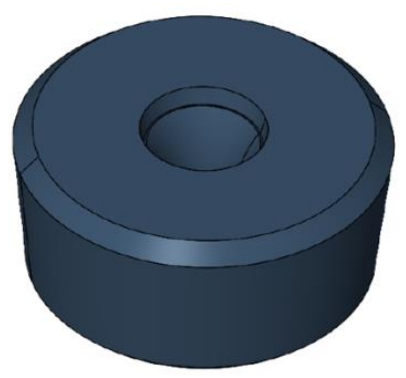

a)

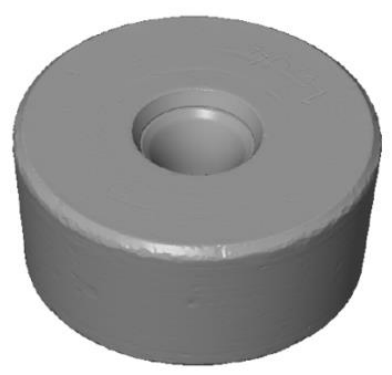

b)

Fig. 4. Drawing die: a) reference CAD model, b) 3D scanned model. 
The 3D scanned model of the weared drawing die (Fig. 4 - right) was compared with the reference CAD model (Fig. 4 - left). The alignment of the digital models was made according to geometric element (all degrees of freedom was taken) [16]. After correct alignment the colour deviation map of shape was obtained (Fig. 5).

\section{Results}

During the handling with the drawing die, the surface wear of the casing occurs. There is also mechanical damage of the surface. The wear represents local changes on colour deviation map of shape (Fig. 5).

Important part of the drawing die is the nib. Wearing occurs on the nib's surface during the production process of tubes. The most weared part of the nib is the area where the reduction of the tube's diameter was happened (Fig. 5 - right, 7, 8).

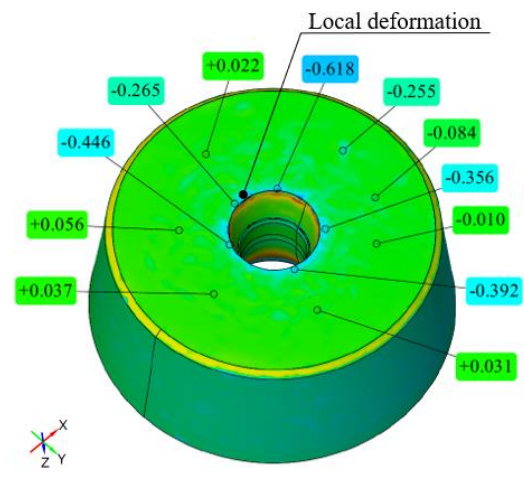

a)

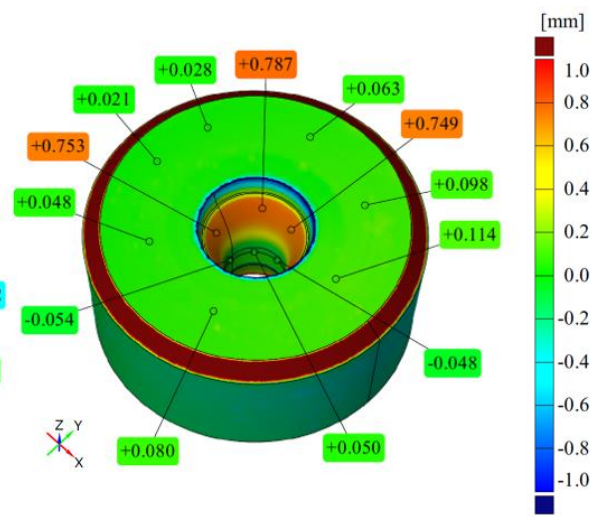

b)

Fig. 5. Colour deviation map of shape, drawing die: a) bottom view, b) top view.

Expect the colour deviation map of shape, generating of inspection sections are possible. On the Fig. 6 are the positions of the inspection sections (Fig. 7, 8) for wear analyzing of drawing die.

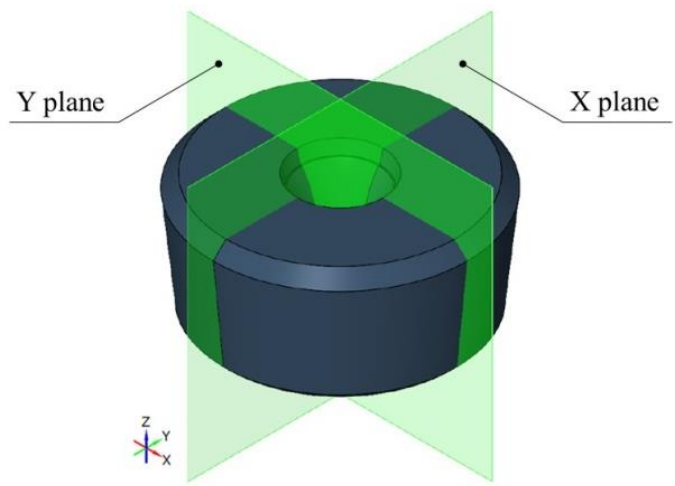

Fig. 6. The positions of the inspection sections (Fig. 7, 8) for wear analyzing of drawing die.

The hole diameter (Fig. 2) was also measured. The Ø18.04 mm hole diameter (nominal diameter) has a manufacturing tolerance of $+0.02 \mathrm{~mm}$. This means that the resulting 
deviation was $+0.03 \mathrm{~mm}$ higher (i.e. $\varnothing 18.09 \mathrm{~mm}$ ), which can lead to the production of poor quality products (i.e. tubes).
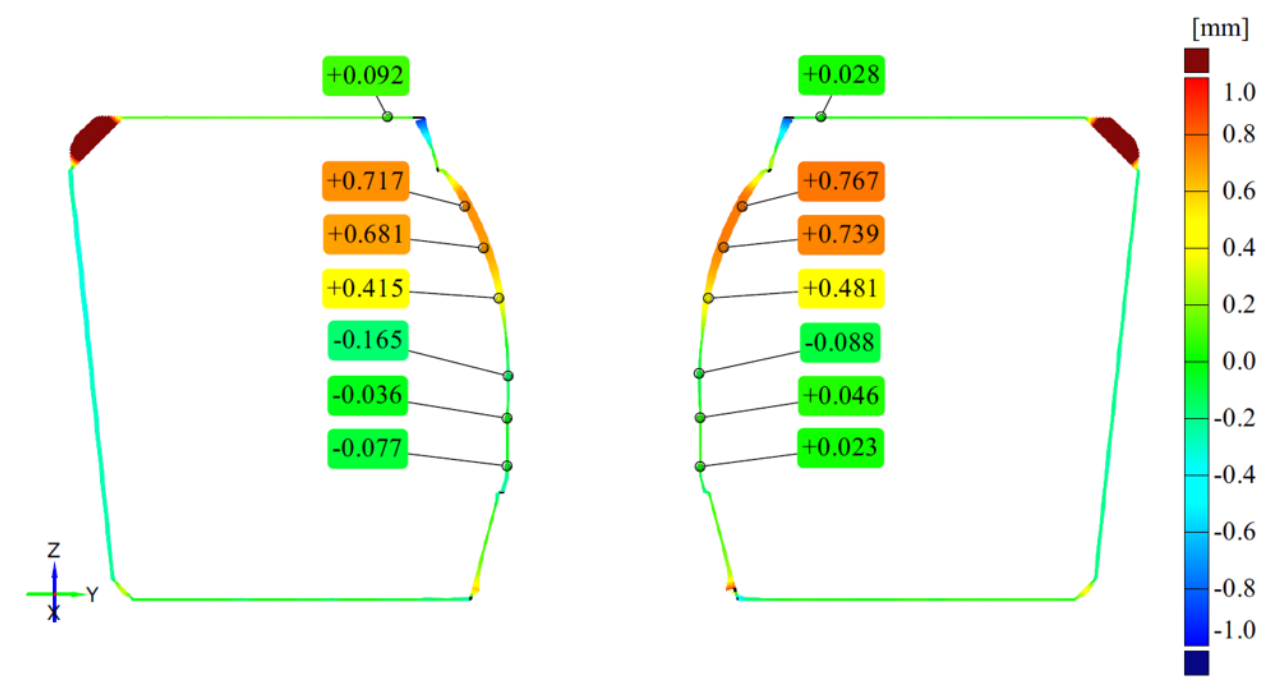

Fig. 7. Inspection section $-\mathrm{X}$ plane.
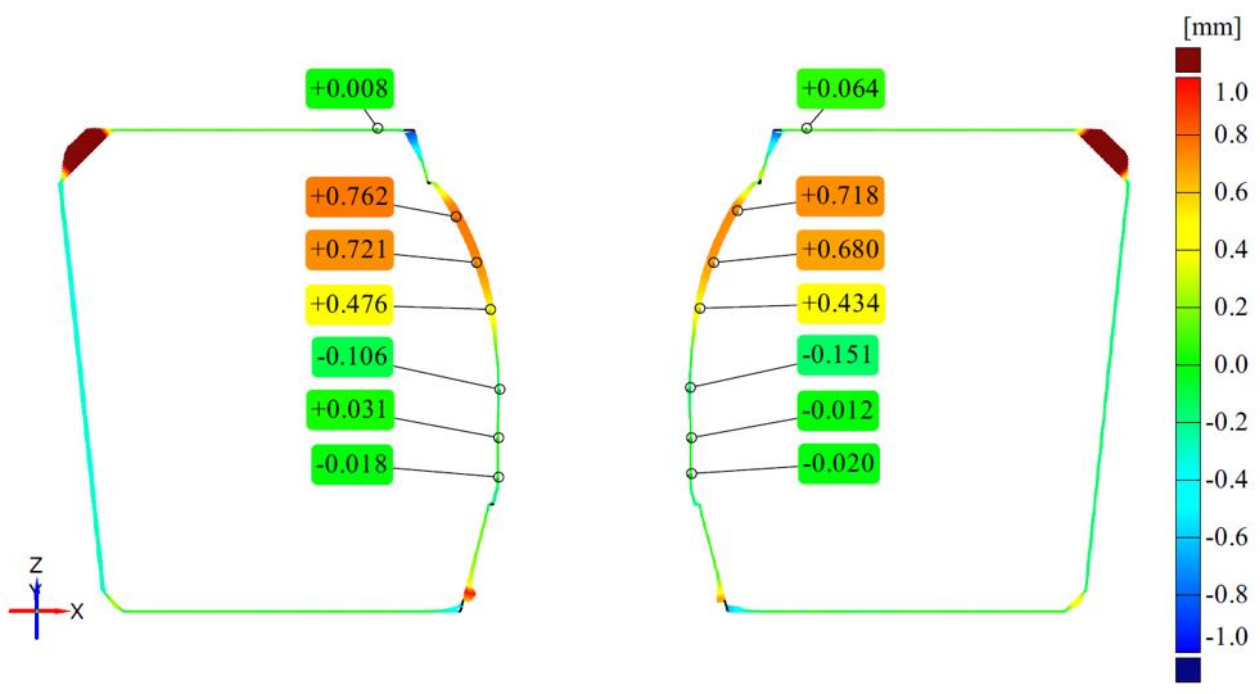

Fig. 8. Inspection section - Y plane.

\section{Conclusion}

The amount of wear depends on a number of factors, for example configuration of tribological pair "tool - tube", method and quality of lubrication, method and speed of drawing, material of tube (type of steel), surface quality of drawn tube, etc.

When optimizing the technological parameters of the drawing of precision tubes, it is necessary to know and quantify the stress-strain states of the tribological pair, which represents the drawing tool and cold drawn precision tubes. Therefore, the research of tribological and tribotechnical aspects of the production process in terms of shape stability of the precision tubes and the material of the tool rests on the analysis of the plastic 
deformations in the drawing of precision tubes. In the research of tool wear, it is also necessary to devote to the development of microstructure using the theory of dislocation in connection with the choice of material and tool geometry and plastic properties of the drawn tube material.

Data analysis shows that 3D scanning accuracy is sufficient not only to evaluate deformations, but also to obtain the shape and surface details of the drawing die. The GOM ATOS II TripleScan SO MV170 is fully versatile in the evaluation of the wear of drawing die.

The research will be extended by further measurements (3D digitization) of additional drawing dies for wear (shape distortion) analyzing. Another important aspect is the shape stability of the produced tubes and the effects of the tool wear on the produced tubes.

Acknowledgement: This work was supported by the Slovak Research and Development Agency under the Contract no. APVV-18-0418. Project title: Research on causes of geometrical deviations in the production of seamless tubes and their technological inheritance with emphasis on the shape stability of precision cold drawn tubes using metrological systems.

\section{References}

1. P. Bere, O. Nemes, C. Dudescu, P. Berce, E. Sabau, Advanced Engineering Forum, 89, 207-214 (2013)

2. P. Bere, E. Sabau, L. Hancu, A. Popescu, Academic Journal of Manufacturing Engineering, 11, 128-131 (2013)

3. V. A. Ceclan, N. Bâlc, S. Grozav, P. Bere, C. Ş. Borzan., Advanced Engineering Forum, 8-9, 215-224 (2013)

4. V. A. Ceclan, S. Grozav, E. Sabau, A. Popan, C. Ş. Borzan., Academic Journal of Manufacturing Engineering, 11, 56-69 (2013)

5. M. Ridzon̆, The Effect of Technological Parameters Influencing the Properties of Seamless Cold-Drawn Tubes, 89 (2012)

6. M. Ridzoň, M. Mojžiš, L. Domovcová, J. Bílik, L'. Parilák, Metal 2015 (2015)

7. N. Bay, A. Azushima, P. Groche, I. Ishibashi, M. Merklein, M. Morishita, T. Makamura, S. Schmid, M. Yoshida, CIRP Annals, 59, 760-780 (2010)

8. D. Tsutsumi, D. Gyulai, A. Kovács, B. Tipary, Y. Ueno, Y. Nonaka, L. Monostori, CIRP Annals, 67, 441- 446 (2018)

9. P. Groche, N. Moeller, H. Hoffmann, J. Suh, Wear, 271, 2570-2578 (2011)

10. ASM - ASM Handbook, Properties and selection: Iron, Steels, and High-Performance Alloys, ASM International, 1063 (1990)

11. A. Humár, Materiály pro řezné nástroje (Materials for cutting tools), 192 (2006). [cit. 03. 06. 2019]. Available at: http://ust.fme.vutbr.cz/obrabeni/opory-save/ mat_pro_rez_nastroje/materialy_pro_rezne_nastroje_v2.pdf

12. L. Morovič, Návrh, obrábanie, meranie a skenovanie tvarovo zložitých plôch (Design,machining, measuring and scanning of free form surfaces), 133/172 (2013)

13. L. Morovič, Non-Contact Measurement of Free-Form Surfaces, 89 (2016)

14. I. Buranský, E. Buranská, Materials Science Forum, 919, 411-419 (2018)

15. D. Paloušek, M. Omasta, D. Koutný, J. Bednář, T. Koutecký, F. Dokoupil, Optical Materials, 40, 1 (2015)

16. GOM - ATOS - V7.5 SR2 Manual - Advanced - Scanning with ATOS - Advanced / Units $A$ - C. 44 (2013). [cit. 11. 06. 2019]. Available at: https://support.gom.com 